\title{
Caregiver reactions and social provisions among family members caring for home-dwelling patients with cancer in the palliative phase: A cross-sectional study
}

\author{
Marianne Fjose*1, Grethe Eilertsen², Marit Kirkevold ${ }^{3}$, Ellen K. Grov ${ }^{1,4}$ \\ ${ }^{1}$ Western Norway University of Applied Sciences, Faculty of Health and Social Sciences, Department of Health and Caring \\ Sciences, Bergen, Norway \\ ${ }^{2}$ University College of Southeast Norway, Faculty of Health and Social Sciences, Department of Nursing and Health Sciences, \\ Norway \\ ${ }^{3}$ University of Oslo, Faculty of Medicine, Department of Nursing Science, Oslo, Norway \\ ${ }^{4}$ Oslo Metropolitan University, Faculty of Health Sciences, Institute of Nursing and Health Promotion, Oslo, Norway
}

Received: May 10, 2019

DOI: $10.5430 /$ cns.v7n $4 \mathrm{p} 1$
Accepted: July 8, 2019

URL: https://doi.org/10.5430/cns.v7n4p1

\begin{abstract}
Objective: Studies focusing on the impact of caregiving for older adult home-dwelling patients with cancer in the palliative phase, particularly the burdens on different family caregiver groups, are limited. The objective of this study was to assess and compare caregiver reactions and social provisions among different family caregiver groups in Norway.

Methods: The sample consisted of 58 family members caring for 26 home-dwelling older adult patients with advanced cancer. The Caregiver Reaction Assessment and Social Provisions Scale were used to assess the caregiver reactions and social support, respectively. The analyses were performed using descriptive statistics.

Results: Significant differences were revealed between the family caregiver groups in the following three dimensions of the Caregiver Reaction Assessment: impact on schedule, lack of family support and impact on health. Significant differences were revealed between the family caregiver groups in the following two dimensions of the Social Provisions Scale: nurturance and attachment.

Conclusions: In our study, children and children-in-law caring for widowed patients and spouses were the most vulnerable family caregivers. We recommend assessing the caregiver situation of all available family members caring for older adult patients with advanced cancer to identify the most vulnerable caregivers.
\end{abstract}

Key Words: Caregiver reaction, Social provisions, Family relationship, Family caregiver group, Cancer, Palliative phase

\section{INTRODUCTION}

Cancer can be divided into two overall phases, i.e., the curative phase and palliative phase. The palliative phase typically "starts with the recognition of incurable disease and continues until the patient dies". [1] Three-quarters of all patients with cancer in the palliative phase are 65 years old or older. ${ }^{[2,3]}$ The increased number of older adults, longer survival, health care policies that emphasize community care ${ }^{[4,5]}$ and the patients' wishes to remain at home even during the palliative phase ${ }^{[6,7]}$ place heavy demands on family caregivers.

\footnotetext{
*Correspondence: Marianne Fjose; Email: Marianne.fjose@hvl.no; Address: Western Norway University of Applied Sciences, Faculty of Health and Social Sciences, Department of Health and Caring Sciences, Bergen, Norway. 
Due to comorbidities, these demands can be physical, social, emotional and financial. ${ }^{[8,9]}$

The patient's situation and ability to remain at home are determined by access to support and care, family caregivers' ability to provide such support and care, ${ }^{[10]}$ and family caregivers' experience with caregiving. ${ }^{[11]}$ Older adult patients may have lost their spouses, or their spouses may be frail and unable to provide care. Therefore, children and/or other close family members are given more caregiving responsibility ${ }^{[8]}$ Caregiving may physically, psychologically, socially and existentially affect the caregivers. ${ }^{[5,11]}$ Caregiving can have positive effects, such as the promotion of maturation and growth. ${ }^{[5]}$ However, caregiving is also associated with negative effects, such as stress, anxiety, depression, fatigue, family conflict and health problems. ${ }^{[12,13]}$ Negative caregiver reaction is described as: "a multidimensional biopsychosocial reaction resulting from an imbalance of care demands relative to the caregivers' personal time, social roles, physical and emotional states, financial resources, and formal care resources given the other multiple roles they fulfill" (s. 1106). ${ }^{[14]}$

Several measures have been developed to assess the reactions of caregivers caring for a sick family member. ${ }^{[11,15,16]}$ Studies have been performed in different contexts and have focused on the frail elderly, dementia care, and mental illness. ${ }^{[16-18]}$ In the context of advanced cancer, both crosssectional and longitudinal studies have been performed, and most studies have assessed the patient and caregiver characteristics and the effects of these characteristics on caregiver reactions. ${ }^{[19-24]}$

Family members with different relationships to a patient, e.g., spouses, children and children-in-law, may experience caregiving differently. ${ }^{[8,25]}$ In addition, the primary caregiver may have a different experience with caregiving than family members who support the primary caregiver or family caregivers who have equal caregiving responsibility. ${ }^{[8]}$ However, only a few studies have assessed and compared caregiver reactions across different family caregiver groups in the context of cancer. ${ }^{[8,14,26-28]}$ According to several literature reviews, studies investigating cancer caregiving have mostly involved one family member per patient, i.e., the person defined as the primary caregiver. Typically, this person is the patient's spouse or daughter. However, sons, other family members and friends have also been investigated. ${ }^{[10,12,29]}$ Only one study performed by Lowenstein and Gilbar ${ }^{[8]}$ compared the caregiver reactions of a patient's spouse and children. The spouse exhibited the most severe caregiver reactions. However, the patients were newly diagnosed with cancer and in the initial stage of the illness. Lund et al. ${ }^{[28]}$ compared the ex- periences of different family caregiver groups (e.g., spouses, parents and children) with caregiving tasks and the consequences of their role and function. The authors recruited more than one caregiver for approximately one third of the 415 cancer patients at various disease stages and found that the spouses experienced the highest workload. Other studies comparing different family caregiver groups recruited one family caregiver per patient and found that adult children exhibited the most severe caregiver reactions. ${ }^{[14,26,27]}$ Kim et al. ${ }^{[27]}$ recruited caregivers of cancer survivors and found that daughters experienced the most stress as a result of caregiving, followed by spouses, and sons experienced the lowest level of caregiver stress. Except for the study conducted by Lowenstein and Gilbar, ${ }^{[8]}$ we could not identify studies comparing the caregiver reactions of different family caregiver groups caring for older adult home-dwelling patients with cancer.

Social support in different contexts, such as cancer and heart disease, positively affects illness and health. ${ }^{[30-32]}$ Social support is conceptualized as "the functions that are provided by social relationships". ${ }^{[33]}$ According to Wright and Leahey, ${ }^{[34]}$ family is an essential source of support because family members protect, nurture and socialize with each other. According to the theoretical model proposed by Weiss, ${ }^{[35]}$ different relationships meet different inter-relational needs. The following six dimensions of social provisions were defined: attachment, social integration, reassurance of worth, opportunity for nurturance, guidance and reliable alliance. These dimensions describe how different relationships provide different types of social support. ${ }^{[35]}$ The social provisions of attachment are mainly provided by the spouse, other family members and close friends, and social integration is mainly provided by friends and spouses. Weiss ${ }^{[35]}$ suggested that all six dimensions are needed, but the relative importance of the dimensions may differ depending on the personality, beliefs, situations and life stages of the individual.

Several studies consider social support a buffering factor in providing care for a family member with advanced cancer and report that satisfactory social support diminishes caregiver burden. ${ }^{[23,24,26,36-39]}$ In contrast, one study conducted in Norway ${ }^{[40]}$ found that high levels of social provisions did not decrease caregiver burden. However, the abovementioned studies did not compare the caregiver burden among different family caregiver groups.

Knowledge regarding how family members with different patient relationships, such as spouses and children/children-inlaw, and children/children-in-law related to patients with or without an available spouse experience the caregiver situation and social provisions is lacking. Thus, studies investigating 
these experiences in the context of home-dwelling patients with cancer in the palliative phase are warranted. ${ }^{[5,11,17]}$ Therefore, the aim of this study is to assess and compare caregiver reactions and social provisions among different family caregiver groups caring for home-dwelling older adult cancer patients during the palliative phase.

\section{Methods}

\subsection{Study design and sample}

This cross-sectional study was performed between February 2012 and November 2013. Nurses working in hospital wards, out-patient units and district services in Western and Eastern Norway invited patients and potential family members to participate in the study. We used the following well-known definition of "family": whoever the patient claims is a member of his/her family. ${ }^{[34]}$ Non-ethnic Nordic families are rare in Western Norway. Therefore, to ensure homogeneity, eligible families included ethnic Nordic families with one family member aged $\geq 65$ years who was diagnosed with cancer in the palliative phase and cared for at home. Co-morbidities were not included in the exclusion criteria. The patients who were willing to participate decided in collaboration with their families, which family members over the age of 18 would participate in the study.

This is an exploratory study and we have no exact outcome targets on the extent of the changes we can expect. It is therefore difficult to perform an exact power calculation. However, to enable ourselves to indicate how many family units we needed to recruit, we performed a power calculation. We set the $\alpha$-value at 0.05 with a strength of 0.80 and the ability to identify differences, Cohen's $d=0.80^{[41]}$ (http: //www . da nielsoper.com/statcalc/calc47.aspx). The calculation shows that we needed 24 participants per family group. We therefore assumed that we needed to recruit 25-30 family units, and we managed to recruit 26 family units, with an average of 3 family members per patient.

\subsection{Demographics and measures}

Data regarding the patients' and family members' sociodemographic characteristics were collected. The patient characteristics included age, gender, cancer type and palliative phase, and the family members' characteristics included age, gender, geographic distance to the patient, education level, employment status, marital status and relationship to the patient.

\subsubsection{The Caregiver Reaction Assessment}

One of the two outcome variables in this analysis was family members' caregiver reactions, which was measured using the Caregiver Reaction Assessment developed by Given et al. in 1992. ${ }^{[42]}$ This questionnaire consists of 24 items and

Published by Sciedu Press assesses the following 5 dimensions: self-esteem ( 7 items), lack of family support (5 items), financial impact (3 items), impact on daily schedule (5 items) and impact on health (4 items). The family members responded on a 5-point Likert scale with 1 indicating strongly disagree, 2 indicating disagree, 3 indicating neither agree nor disagree, 4 indicating agree, and 5 indicating strongly agree. The composite score of each dimension is the mean rating of the items in each dimension (range from 1.0 to 5.0). The subscale of family member's self-esteem measures the positive experiences of caregiving, and a lower score indicates greater burden. The other four subscales assess the negative experiences of caregiving, and higher scores indicate higher levels of burden. The Caregiver Reaction Assessment has been widely used in studies investigating advanced cancer caregiving and has been psychometrically tested and validated, ${ }^{[11,15-17]}$ including in Norway. ${ }^{[20,40]}$ The psychometric properties have been reported to be satisfactory using the same dimensions as the original version. Permission to use the Norwegian version of the instrument was obtained from Grov (2011).

\subsubsection{The Social Provisions Scale}

To examine the availability of social provisions, the revised Social Provisions Scale ${ }^{[43]}$ was used to measure the second outcome variable. This scale originally consisted of 24 items and six dimensions. ${ }^{[35]}$ Two dimensions (i.e., reliable alliance and guidance) were highly correlated with the other dimensions; therefore, these dimensions have been omitted from the revised Social Provisions Scale. ${ }^{[43]}$ The revised Social Provisions Scale consists of 16 items, including 4 items covering each of the following four dimensions: attachment, social integration, opportunity for nurturance and reassurance of worth. The family members responded on a four-point Likert scale with the following response options: strongly agree $=4$, agree $=3$, disagree $=2$, and strongly disagree $=1$. Higher scores indicate higher levels of social provision. The Social Provisions Scale has been used in studies investigating cancer caregiving and gerontology. ${ }^{[30,32,40,44]}$ Psychometric testing of the Norwegian version of the Social Provisions Scale using confirmatory factor analysis sustains the factor structure suggested in the revised 16-item Social Provisions Scale. ${ }^{[4]}$ Permission to use the Norwegian version of the instrument was obtained from Bondevik (2011).

\subsection{Procedures}

Because this topic is sensitive and complex ${ }^{[46]}$ and recruiting large family units may be difficult, ${ }^{[47]}$ we attempted to recruit four family members per patient. The first author was present in the patients' homes during data collection. The family caregivers were instructed about how to interpret the different questions and informed that we were interested in their 
experiences with each item. If the participants required assistance due to difficulties in understanding the questions, the researcher (the first author) provided clarification or helped the participants complete the questionnaires. A few spouses needed assistance.

\subsection{Statistical analyses}

The data were analysed using SPSS version 24 (SPSS Inc., Chicago, IL). To determine the reactions of the family caregivers to caregiving and perceived social provisions, we first examined the data, particularly the skewness and kurtosis statistics, which had low values indicative of normal distributions. The mean and median values were mostly similar. However, we performed both non-parametric (MannWhitney $U$-tests) and parametric ( $t$-tests) tests to evaluate each item and dimension of the assessment tools. In the group comparisons, all p-values were consistent, except for item 11 on the Caregiver Reaction Assessment in the comparison of the spouses and children (0.04 [ $t$-test] versus 0.08 [U-test]). Because we sought to compare our results with other studies reporting mean values and SDs of the Caregiver Reaction Assessment, we therefore show mean and $S D$ values for each item, and the corresponding p-values to present the possible differences between the groups in this study. Furthermore, a Spearman's rho correlation analysis of the dimensions on the Caregiver Reaction Assessment and Social Provisions Scale was performed. To compare the caregiver reactions and social provisions of family members with different relationships to the patients, the following caregiver groups were constructed: spouses and children/children-inlaw. Due to the low number of participants, we were unable to construct separate daughter, son and children-in-law groups. To explore whether the availability of a patient's spouse affected the children and children-in-law caregiver reactions and social provisions, the following two groups were constructed: children/children-in-law of married patients $(\mathrm{ChmP})$ and children/children-in-law of widowed patients (ChwP). The level of significance was set at $p<.05$ and all tests were two-sided.

\subsection{Ethics}

Families where an elderly family member has cancer in the palliative phase, are in a vulnerable phase of life. Therefore, this study was conducted according to the Declaration of Helsinki (2013). Also, The Regional Committees for Medical and Health Research Ethics in Norway approved the study: 2011/1731a. To ensure voluntariness, nurses handed out information letters with a consent form to potential patients and family members. Families willing to participate sent the consent form to the first author or gave the nurse permission to give the author their phone number. All partic- ipants were informed (both verbally and through the written information letter) of their right to withdraw their participation at any time. All family members provided informed consent to participate in the study.

\section{RESULTS}

\subsection{Sample}

In total, 75 information letters were distributed to eligible families, and 33 families consented to participate. Seven families withdrew before the day of the interview because of the patient's impaired health status. No families withdrew their consent during or after data collection. Thus, 26 families participated in this study.

The sample consisted of 58 family members caring for 26 older adult patients with cancer in a palliative phase with a mean of 3 (range 1-4, median 3) family members per patient. Thirteen patients were women, and 13 patients were men. Fourteen spouses, two children and one son-in-law lived in the same household as the patient. Among the family members who did not reside in the same household as the patient, the mean distance to the patient's home was 8.26 miles (range 0-68.3 miles, median 2.5 miles). Only one of the employed family members was a spouse. The patients' cancer sites included lung, ${ }^{[7]}$ prostate, ${ }^{[6]}$ colon $^{[6]}$ and other. ${ }^{[7]}$ Most (69\%) patients displayed comorbidity. Fifteen patients were diagnosed within two years of the interview, and 13 patients had metastatic cancer at the time of diagnosis. Of the spouses, $30 \%$ had multiple diagnoses. Tables 1 and 2 display the demographic characteristics of the families. In Table 1, all family members are classified according to their relation to the patient.

\subsection{Differences in the dimensions and single items of the Caregiver Reaction Assessment between family care- giver groups}

Significant differences were revealed between the caregiver groups in the following three (of five) Caregiver Reaction Assessment dimensions: impact on schedule, lack of family support and impact on health (see Figures 1-4). To illustrate the differences in the single items of the Caregiver Reaction Assessment, the means, $S D$ and $p$-values of all caregiver groups studied are presented in Tables 3 and 4.

\subsubsection{Impact on schedule}

The spouses exhibited significantly higher scores on the disrupted schedule dimension than the children/children-in-law, $p=.013$ and ChmP, $p=.009$. The results of the schedule dimension are presented as single items. The spouses exhibited significantly higher scores on item 4 ("my activities are centred on care") and item 14 ("eliminate from schedule") than the children/children-in-law and ChmP. The spouses 
also scored significantly higher on item 18 ("interruptions") than the ChmP.

Table 1. Sociodemographic characteristics of the participants

\begin{tabular}{lll}
\hline Characteristic & Mean & Range \\
\hline Participants' age (N= 84) & 78.7 & $(65-92)$ \\
Patients & 73.3 & $(55-84)$ \\
Spouses & 48.6 & $(33-56)$ \\
Sons & 45.9 & $(27-62)$ \\
Daughters & 63 & \\
Sons-in-law & 44.5 & $(34-53)$ \\
Daughters-in-law & $\mathbf{n}$ & $\mathbf{\%}$ \\
\hline Characteristic & 10 & 16 \\
\hline Relationship of the family member to the patient & $\mathbf{N}=\mathbf{5 8})$ \\
Wife & 4 & 7 \\
Husband & 11 & 18 \\
Son & 26 & 43 \\
Daughter & 1 & 2 \\
Son-in-law & 6 & 10 \\
Daughter-in-law & & \\
Children's marital status (N = 37) & & 65 \\
Married & 24 & 35 \\
Unmarried & 13 & \\
Family members' educational level (N = 58) & \\
High school or above & 31 & \\
Below high school & 29 & \\
Family members' employment status (N = 58) & \\
Employed full-time or part-time & 45 & \\
Retired, sick leave or unemployed & 15 & \\
\hline & & \\
\hline
\end{tabular}

Table 2. Clinical variables of the patients and their spouses

\begin{tabular}{lllllc}
\hline & \multicolumn{2}{l}{ Patients } & & & $\begin{array}{c}\text { Domestic } \\
\text { partners }\end{array}$ \\
\cline { 1 - 1 } \cline { 5 - 5 } Cancer types & & Other diseases & & & Other diseases \\
\hline Lung & 7 & Cardiovascular diseases & 10 & & 4 \\
Prostatic & 6 & Polymyalgia & 1 & \\
Breast & 1 & Hearing impairment & 4 & & 1 \\
Colon & 6 & Musculoskeletal diseases & 9 & & 6 \\
Amyloidosis & 1 & Mental diseases & 1 & \\
Gynaecologic & 1 & Cerebri diseases & 4 & 2 \\
Mole & 2 & Renal failure & 1 & 1 \\
Bone marrow & 1 & COPD, asthma & 3 & \\
CML & 1 & Diabetes & 2 & 2 \\
Myelomatosis & 1 & Vision impairment & 1 & \\
Unknown & 1 & Chron's disease & 1 & \\
\hline
\end{tabular}




\subsubsection{Lack of family support}

Regarding the dimension of lack of family support, the children/children-in-law reported significantly greater burden than the spouses, $p=.010$. In addition, the ChwP reported significantly higher levels of burden than the spouses, $p=$ .004. Regarding the single items, the children/children-inlaw scored significantly higher than the spouses on item 2 ("others dumping care on me") and item 22 ("family left me alone"), providing insight into the detailed aspects of the lack of family support dimension. The ChwP exhibited significantly higher scores than the spouses on items 2 and 16 ("feel abandoned"), and higher scores than both the spouses and ChmP on item 22.

\subsubsection{Impact on health}

The ChwP exhibited significantly higher scores on the impact on health dimension than the children/children-in-law of married patients, $p=.040$. The ChwP exhibited significantly higher scores than the ChmP on item 5 ("tired all the time") and item 10 ("health has gotten worse") and higher scores than the spouses on item 19 ("healthy enough to care"). Furthermore, the spouses scored significantly higher than the ChmP on items 5 and 10.

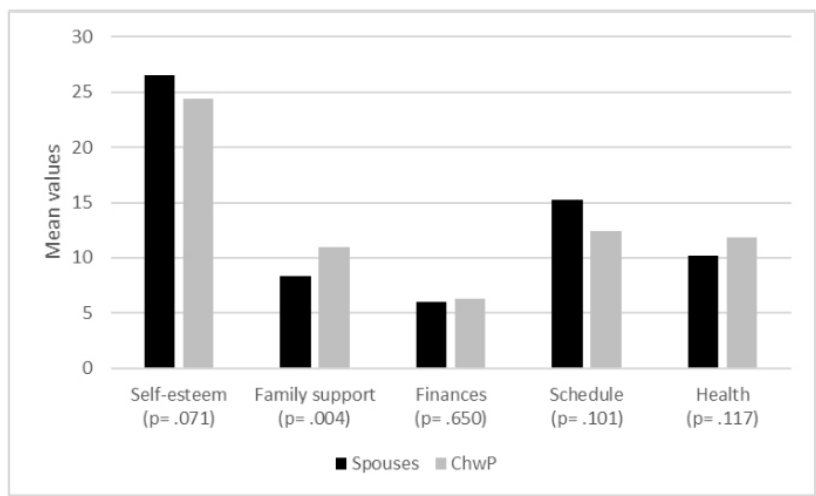

Figure 4. Comparison of mean values of dimensions on the Caregiver Reaction Assessment between spouses and ChwP

Table 3. Comparison of single items on the Caregiver Reaction Assessment between different family caregiver groups

\begin{tabular}{|c|c|c|c|}
\hline \multirow{2}{*}{ Items } & Spouses $(n=14)$ & Children/children-in-law $(n=44)$ & \multirow{2}{*}{$p$-value } \\
\hline & mean $(S D)$ & mean $(S D)$ & \\
\hline 1. Privilege to care & $4.79(0.43)$ & $4.23(0.74)$ & .010 \\
\hline 2. Others dump caring & $1.21(0.58)$ & $1.82(0.97)$ & .032 \\
\hline 3. Finances adequate & $3.29(1.54)$ & $2.91(1.44)$ & .406 \\
\hline 4. Activities centred on care & $3.36(1.15)$ & $2.59(0.1 .00)$ & .019 \\
\hline 5. Tired all the time & $2.64(0.84)$ & $2.41(1.19)$ & .498 \\
\hline 6. Difficult to get help & $1.50(1.09)$ & $1.70(0.88)$ & .478 \\
\hline 7. Resent having to care & $2.29(1.54)$ & $2.27(1.55)$ & .978 \\
\hline 8. Stop work to care & $2.29(1.44)$ & $2.11(0.97)$ & .611 \\
\hline 9. Want to care & $4.14(1.17)$ & $3.98(0.95)$ & .594 \\
\hline 10. Health has gotten worse & $2.21(1.31)$ & $1.64(0.81)$ & .052 \\
\hline 11. Visit family/friends less & $3.21(1.72)$ & $2.30(1.29)$ & .037 \\
\hline 12. Never do enough to repay & $3.29(1.44)$ & $3.02(1.28)$ & .519 \\
\hline 13. Family works together & $3.29(1.59)$ & $3.45(1.13)$ & .662 \\
\hline 14. Eliminate from schedule & $3.50(1.60)$ & $2.57(1.35)$ & .036 \\
\hline 15. Physical strength & $2.50(1.34)$ & $3.27(1.40)$ & .075 \\
\hline 16. Feel abandoned & $1.14(0.36)$ & $1.55(0.76)$ & .062 \\
\hline 17. Caring makes me feel good & $3.86(1.10)$ & $3.89(0.89)$ & .920 \\
\hline 18. Interruptions & $2.86(1.10)$ & $2.25(1.10)$ & .078 \\
\hline 19. Healthy enough to care & $2.79(1.19)$ & $3.50(1.59)$ & .128 \\
\hline 20. Caring is important to me & $4.29(0.73)$ & $4.09(0.77)$ & .408 \\
\hline 21. Financial strain & $1.43(0.76)$ & $1.52(0.76)$ & .688 \\
\hline 22. Family left me alone & $1.14(0.36)$ & $1.73(0.90)$ & .022 \\
\hline 23. Enjoy caring & $3.86(0.95)$ & $3.91(0.80)$ & .841 \\
\hline 24. Difficult to pay & $1.29(0.61)$ & $1.59(0.84)$ & .217 \\
\hline
\end{tabular}


Table 4. Comparison of single items of the Caregiver Reaction Assessment for different family caregiver groups

\begin{tabular}{|c|c|c|c|c|c|c|c|c|c|}
\hline \multirow[t]{2}{*}{ Items } & $\begin{array}{c}\text { Spouses } \\
\mathrm{n}=14\end{array}$ & $\begin{array}{l}\text { ChmP }^{*} \\
n=22\end{array}$ & \multirow[t]{2}{*}{$p$-value } & $\begin{array}{c}\text { Spouses } \\
\mathrm{n}=14\end{array}$ & $\begin{array}{l}\text { ChwP }^{\text {F* }} \\
\text { n }=15\end{array}$ & \multirow[t]{2}{*}{$p$-value } & $\begin{array}{l}\text { ChmP }^{*} \\
\text { n }=22\end{array}$ & $\begin{array}{c}\text { ChwP }^{* *} \\
\mathrm{n}=15\end{array}$ & \multirow[t]{2}{*}{$p$-value } \\
\hline & mean $(S D)$ & mean $(S D)$ & & mean $(S D)$ & mean $(S D)$ & & mean $(S D)$ & mean $(S D)$ & \\
\hline 1. Privilege to care & $4.79(0.43)$ & $4.27(0.70)$ & .019 & $4.79(0.43)$ & $4.13(0.83)$ & 0.014 & $4.27(0.70)$ & $4.13(0.83)$ & .586 \\
\hline 2. Others dump caring & $1.21(0.58)$ & $1.59(0.91)$ & .177 & $1.21(0.58)$ & $1.93(0.88)$ & 0.016 & $1.59(0.91)$ & $1.93(0.88)$ & .263 \\
\hline 3. Finances adequate & $3.29(1.54)$ & $2.68(1.39)$ & .232 & $3.29(1.54)$ & $3.20(1.57)$ & 0.883 & $2.68(1.39)$ & $3.20(1.57)$ & .298 \\
\hline 4. Activities centred on care & $3.36(1.15)$ & $2.45(0.96)$ & .016 & $3.36(1.15)$ & $2.60(1.18)$ & 0.092 & $2.45(0.96)$ & $2.60(1.18)$ & .683 \\
\hline 6. Difficult to get help & $1.50(1.09)$ & $1.55(0.67)$ & .878 & $1.50(1.09)$ & $1.80(1.08)$ & 0.464 & $1.55(0.67)$ & $1.80(1.08)$ & .382 \\
\hline 7. Resent having to care & $2.29(1.54)$ & $2.32(1.73)$ & .955 & $2.29(1.54)$ & $2.27(1.49)$ & 0.973 & $2.32(1.73)$ & $2.27(1.49)$ & .926 \\
\hline 8. Stop work to care & $2.29(1.44)$ & $1.91(0.87)$ & .332 & $2.29(1.44)$ & $2.27(1.22)$ & 0.970 & $1.91(0.87)$ & $2.27(1.22)$ & .304 \\
\hline 9. Want to care & $4.14(1.17)$ & $4.05(1.00)$ & .791 & $4.14(1.17)$ & $3.80(1.01)$ & 0.405 & $4.05(1.00)$ & $3.80(1.01)$ & .471 \\
\hline 10. Health has gotten worse & $2.21(1.31)$ & $1.41(0.59)$ & .017 & $2.21(1.31)$ & $1.87(0.99)$ & 0.426 & $1.41(0.59)$ & $1.87(0.99)$ & .087 \\
\hline 11. Visit family/friends less & $3.21(1.72)$ & $2.27(1.16)$ & .058 & $3.21(1.72)$ & $2.53(1.60)$ & 0.278 & $2.27(1.16)$ & $2.53(1.60)$ & .569 \\
\hline 13. Family works together & $3.29(1.59)$ & $3.50(1.26)$ & 657 & $3.29(1.59)$ & $3.40(1.18)$ & 0.827 & $3.50(1.26)$ & $3.40(1.18)$ & .810 \\
\hline 14. Eliminate from schedule & $3.50(1.60)$ & $2.55(1.37)$ & .065 & $3.50(1.60)$ & $2.60(1.55)$ & 0.136 & $2.55(1.37)$ & $2.60(1.55)$ & .911 \\
\hline 15. Physical strength & $2.50(1.34)$ & $3.32(1.39)$ & .091 & $2.50(1.34)$ & $3.40(1.50)$ & 0.102 & $3.32(1.39)$ & $3.40(1.50)$ & .866 \\
\hline 16. Feel abandoned & $1.14(0.36)$ & $1.36(0.49)$ & .158 & $1.14(0.36)$ & $1.47(0.74)$ & 0.152 & $1.36(0.49)$ & $1.47(0.74)$ & .614 \\
\hline 17. Caring makes me feel good & $3.86(1.10)$ & $4.00(1.02)$ & .694 & $3.86(1.10)$ & $3.73(0.80)$ & 0.730 & $4.00(1.02)$ & $3.73(0.80)$ & .403 \\
\hline 18. Interruptions & $2.86(1.10)$ & $2.09(0.87)$ & .026 & $2.86(1.10)$ & $2.47(1.51)$ & 0.435 & $2.09(0.87)$ & $2.47(1.51)$ & .342 \\
\hline 19. Healthy enough to care & $2.79(1.19)$ & $3.36(1.65)$ & .264 & $2.79(1.19)$ & $3.80(1.52)$ & 0.057 & $3.36(1.65)$ & $3.80(1.52)$ & .421 \\
\hline 20. Caring is important to me & $4.29(0.73)$ & $4.23(0.69)$ & .809 & $4.29(0.73)$ & $3.93(0.70)$ & 0.196 & $4.23(0.69)$ & $3.93(0.70)$ & .213 \\
\hline 21. Financial strain & $1.43(0.76)$ & $1.50(0.67)$ & .769 & $1.43(0.76)$ & $1.60(0.99)$ & 0.605 & $1.50(0.67)$ & $1.60(0.99)$ & .715 \\
\hline 22. Family left me alone & $1.14(0.36)$ & $1.36(0.58)$ & .213 & $1.14(0.36)$ & $2.13(1.13)$ & 0.004 & $1.36(0.58)$ & $2.13(1.13)$ & .010 \\
\hline 23. Enjoy caring & $3.86(0.95)$ & $3.86(0.77)$ & .982 & $3.86(0.95)$ & $3.80(0.86)$ & 0.866 & $3.86(0.77)$ & $3.80(0.86)$ & .816 \\
\hline 24. Difficult to pay & $1.29(0.61)$ & $1.68(1.00)$ & .191 & $1.29(0.61)$ & $1.40(0.63)$ & 0.625 & $1.68(1.00)$ & $1.40(0.63)$ & .339 \\
\hline
\end{tabular}

Note. ${ }^{*} \mathrm{ChmP}:$ children/children-in-law of married patients; ${ }^{* *} \mathrm{ChwP}$ : children/children-in-law of widowed patients

3.3 Differences in the dimensions and single items of the Social Provisions Scale between the family caregiver groups

Significant differences were revealed in the following two (of four) Social Provisions Scale dimensions: nurturance and attachment. The spouse scores on the nurturance dimension were significantly higher than those of the ChwP, $p=.041$ Regarding the single items, the only significant difference was observed in item 9 ("There is no one who really relies on me for their well-being"), and the ChmP scored higher on this item than the ChwP. The ChmP exhibited significantly higher scores on the attachment dimension than the ChwP, $p=.032$. Regarding the single items, the ChmP exhibited significantly higher scores than the ChwP on item 11 ("I have close relationships that provide me with a sense of emotional security and well-being").

\subsection{Relationship among the Caregiver Reaction Assess- ment and Social Provisions Scale dimensions}

According to a bivariate correlation analysis, the dimensions in the Caregiver Reaction Assessment and Social Provisions Scale were weakly correlated. The highest negative correlation coefficient, Spearman's rho $=-0.236, p=.05$, was found between the lack of family support dimension of the
Caregiver Reaction Assessment and the attachment dimension of the Social Provisions Scale. While this finding may have been random, the relationship could be explained by a conceptual overlap between these two dimensions.

\section{Discussion}

In this study, we assessed and compared caregiver reactions and social provisions between different family caregiver groups caring for older adult patients with cancer in the palliative phase. The main findings include significant differences between the family caregiver groups on the following three (of five) Caregiver Reaction Assessment dimensions: impact on schedule, lack of family support and impact on health. Furthermore, significant differences were observed between the family caregiver groups on the following two (of four) Social Provisions Scale dimensions: nurturance and attachment.

\subsection{Spouses constitute the family caregiver group with the most interrupted schedule}

In the present study, the spouses reported their schedule was interrupted due to their caregiver role more often than the children/children-in-law and ChmP. To the best of our knowledge, the only study using the Caregiver Reaction As- 
sessment to compare caregiver reactions among different family caregiver groups caring for cancer patients during the palliative phase was conducted by Given et al. ${ }^{[14]}$ Their findings revealed that children/children-in-law exhibited higher scores on the interrupted schedule dimension than spouses. A comparison of the mean scores on these dimensions identified a significant difference in impact on schedule between the spouses in Given et al.'s study ${ }^{[14]}$ and the spouses in the present study, $p=.013$ [dimension mean scores of 2.84 ( $S D$ $0.67)$ and 3.04 ( $S D$ 1.02) respectively], and the spouses in this study reported significantly higher levels of burden. This difference could be explained by the age differences in the spouses because $73 \%$ of the caregivers in Given et al.'s study were older than 55 years, while the mean age of the spouses in this study was 73.3 years. Thus, older age may be associated with health problems that could limit resources. ${ }^{[48]}$ Furthermore, Given et al. ${ }^{[14]}$ recruited one family caregiver per patient. If the children/children-in-law in Given et al.'s study ${ }^{[14]}$ cared for widowed patients, this group could be comparable to our ChwP group. However, no significant differences were observed in the interrupted schedule dimension between our spouses and children/children-in-law of widowed patient group.

Our finding that spouses experienced a greater impact on schedule than ChmP may be comparable to Lowenstein and Gilbar's findings ${ }^{[8]}$ because their children group shared caregiving responsibilities with the patient's spouse. Lowenstein and Gilbar found that spouses and children reported equal role strain scores. Role strain reflects "the level of change in various aspects of the caregiver's life, such as having insufficient time for him/herself". ${ }^{[8]}$ However, because Lowenstein and Gilbar used the Caregiver Burden Scale and the patients were in the initial stage of the illness, performing comparisons is difficult. In Lowenstein and Gilbar's study, ${ }^{[8]}$ the mean age of the spouses was 70 years, which is comparable to the age of the spouses in our study; thus cultural differences could explain the differences between the Norwegian and Israeli spouses' experiences with the caregiver situation.

The current study is the only study in the context of cancer to compare different family caregiver groups and report that spouses experience the greatest impact on their schedule. Our results could be explained in terms of cultural diversity. Lowenstein and Gilbar performed their study in Israel, Given et al. ${ }^{[14]}$ performed their study in the USA, and our study was performed in Norway. In Norway, spouses, children and children-in-law are not legally obligated to care for family members. In particular, spouses might consider their role as caregivers a duty, but this view may differ from that of spouses in other countries. Spouses may feel more obligated than children and children-in-law due to several reasons, such as normative expectations of the marital bond suggesting that spouses are primary caregivers, spouses who live with the patient might tend to become more involved in caregiving tasks, and spouses perform additional tasks that were previously performed by the patient. ${ }^{[8]}$ Furthermore, spouses are reluctant to leave the patient alone in case of an emergency ${ }^{[49]}$ and patients and spouses avoid bothering their children. ${ }^{[4,50,51]}$ Notably, the highest significant values were observed in the comparison between the spouses and ChmP. We hypothesize that this result indicates that an available spouse lessens the caregiver burden of children and children-in-law.

\subsection{Children and children-in-law lacking family sup- port}

In the present study, the children/children-in-law and ChwP reported a greater lack of family support than the spouses. This finding is consistent with Given et al.'s study, ${ }^{[14]}$ in which the children/children-in-law reported higher levels of abandonment than the spouses. As previously mentioned, the particular group of children/children-in-law in Given et al.'s study ${ }^{[14]}$ could be comparable to our group of ChwP. Notably, significant differences were observed in the comparison of the ChwP and the spouses, indicating that children and children-in-law caring for a patient with a spouse perceive a lesser degree of lack of family support.

Children/children-in-law and ChwP may lack more family support than spouses for several reasons. According to traditional and cultural family rules, spouses are expected to care for a sick spouse. ${ }^{[48]}$ However, as previously mentioned, patients and spouses often protect children from the caregiver burden $^{[8,25,49,51]}$ and, therefore, likely do not expect children and children-in-law to support them in caregiving. Children and children-in-law are not expected to provide much caregiving; ${ }^{[26]}$ have multiple role obligations, such as home, children and work, in addition to caregiving ${ }^{[25,26,52]}$ and may therefore be in need of help and expect family members to share the caregiving responsibility. ${ }^{[52]}$

\subsection{Caregiver health: are ChwP the most vulnerable group?}

The group of ChwP reported more health problems than the ChmP. To the best of our knowledge, no other studies have reported comparable findings within the context of cancer. The ChwP could have had more health problems. In this case, older age might be an explanation, but no differences was observed in age between the groups, $p=.06$. Another explanation might be that because the ChwP had to spend more time checking on the patient in the absence of a spouse, these participants felt more exhausted. In patients with a 
spouse, the partner is often present to check on the patient and call for help if needed.

Interestingly, although several of the elderly spouses in our study reported the presence of multiple diagnoses, they did not report a greater impact on health than any other group. However, the spouses scored significantly higher than the ChmP on two single items ("tired all the time" and "health has gotten worse"). Thus, the spouses in our study likely expected worsened health due to old age or only related their health problems to their older age and not to caregiving. In several Asian studies, the spouses reported more health problems than non-specific groups of caregivers. ${ }^{[23,53]}$ Additionally, older caregivers tend to report more health problems than young caregivers. ${ }^{[4,36]}$ However, these studies did not compare specific family caregiver groups and only recruited primary caregivers; thus, comparing these studies with our study is challenging.

\subsection{Children and children-in-law of widowed patients perceive lack of social support}

To the best of our knowledge, no published studies have investigated social support among family caregiver groups caring for patients with cancer in the palliative phase, using the Social Provisions Scale. Thus, comparing our findings to other studies is difficult.

The group of ChwP in our study reported significantly lower levels of attachment than ChmP. According to Weiss, ${ }^{[35]}$ attachment provides security and safety and is mainly provided by a spouse, other family members and close friends. Comparing the two groups, more children in the ChwP group lived with a spouse, indicating that the absence of a spouse had no impact on their report on attachment. However, the presence of a spouse does not automatically imply available support. The ChwP group $(\mathrm{n}=21)$ consisted of 6 sons, 6 children-in-law and 9 daughters, and the $\mathrm{ChmP}(\mathrm{n}=23)$ consisted of 17 daughters, 5 sons and 1 child-in-law. The ChwP had fewer family members and friends to provide security and safety. Because the family caregiver group of ChmP mostly consisted of daughters (17 of 23), the ChmP group may have scored higher on the attachment dimension than the ChwP group due to the following reasons: women tend to seek and receive more social support, which is consistent with other studies, ${ }^{[54]}$ and women might have a social network that provides safety and security. Sons tend to primarily rely on one person, i.e., their spouse, for social support. ${ }^{[32]}$ Furthermore, the ChwP may have reported lower levels of attachment due to the forthcoming loss of their last parent. Parents are possible sources of attachment support who they have to support and protect in this situation.
The spouses exhibited significantly higher scores on the nurturance dimension than the ChwP. Nurturance comprises the participants' perception of their responsibility for another person's well-being. ${ }^{[35]}$ The spouses' high score may reflect their caring responsibility for their spouse. According to Weiss, ${ }^{[35]}$ the opportunity to nurture another human being has a positive impact on self-esteem. Interestingly, in this study, the spouses reported significantly higher scores than all other family caregiver groups on the "privilege to care" item of the Caregiver Reaction Assessment self-esteem dimension. Spouses are reluctant to involve others in the patient's care ${ }^{[4]}$ likely because they find it rewarding to support their spouse, which positively affects their self-esteem.

\subsection{Study strengths and limitations}

Given the lack of studies differentiating specific family relationships to the patient, one strength of this study is the assessment performed using standardized instruments and analyses comparing different caregiver groups. Analyzing each item of the two instruments resulted in many tests. However, this study is explorative, and similar studies have never been performed; thus, analyzing the items and dimensions in each caregiver group is valuable. Further studies should include more respondents and larger groups to enable multiple testing.

The correlation among the dimensions of the Caregiver Reaction Assessment and Social Provisions Scale were weak, indicating that the two instruments cover different main concepts, i.e., caregiver reactions and social provisions, respectively. The researcher's availability while the participants were completing the questionnaire ensured that all items were completed. The weakness of this study is the number of respondents. We attempted to recruit four family members per patient. This delimitation may have resulted in recruiting fewer participants, more participants would have likely been included if we performed open recruitment and included everyone in the family who wanted to participate. To ensure robust groups in the statistical analyses, we were unable to separate the sons, daughters and children-in-law into specific groups. Including families with different numbers of participants into the group "children/children-in-law" introduced bias in representability because the families had unequal weight in the analyses. Recruitment for studies involving patients with cancer in the palliative phase has been reported to be challenging, ${ }^{[23,26,55]}$ which was the case in this study. Although we used a wide definition of family in the recruitment process, the sample consisted of only biological and intermarried family members. This sample may exist because the nurses who recruited the families asked only biological families to participate. In addition, most families are 
from rural Norway, where biological families are the most common type of families, representing the homogeneity of the family structure in Norway.

\subsection{Practical implications and future studies}

Providing care to an elderly home-dwelling family member with advanced cancer is a demanding task ${ }^{[8,10,14,16]}$ that may result in burden on all close family members. In this study, the nature and severity of the burden varied across family members with different relationships to the patient (e.g., spouses and children/children-in-law) and between children/children-in-law of married and widowed patients. Thus, the family members' relationship to the patient and family structure may inform which interventions are beneficial. To help family members manage caregiving and target interventions, health care professionals should assess the impact of caregiving on all available family members.

Because the study of the burden of caregiving among different family caregiver groups is in its infancy, further studies are needed to clarify the nature and severity of the stress experienced and how this stress varies as a function of the family structure and the caregiver's relationship to the patient. Qualitative studies are needed to obtain deeper insight into how different family caregiver groups experience the caregiving situation, how different family members organize their caregiving and what factors affects their attitudes and actions. Further studies should also emphasize activities of daily living during the patient's trajectory, particularly the end-of-life, and how this affects the caregiver relationship and the caregiver burden.

\section{Conclusions}

Caregiving affects all close family members of homedwelling older adult patients with advanced cancer, and in this study, specific family caregiver groups expressed this burden differently. The elderly spouses reported the greatest impact on schedule. The children/children-in-law and ChwP reported the greatest lack of family support, and the latter group also reported the greatest impact on health. Therefore, children and children-in-law caring for widowed patients and spouses were the most vulnerable family caregivers in our study. This perspective on family caregivers' self-reported burden adds to the family caregiving field because our assessment and analysis included several different caregiver groups.

\section{FUNDING}

This project is funded by a research career grant to Marianne Fjose (Grant No. 2010/754-5806/2010), Western Norway University of Applied Sciences, Faculty of Health and Social Sciences, Department of Health and Caring Sciences, Førde, Norway. Previous Sogn and Fjordane University College, Faculty of Health Studies, Førde, Norway.

\section{CONFlicts of INTEREST Disclosure}

The authors declare they have no conflicts of interest.

\section{REFERENCES}

[1] EAPC. Definition of palliative care. Cited 2016 Mar 2. Available from: Eapcnet.eu/Corporate/AbouttheEAPC/Def intionand Aims.aspx

[2] Cancer Research UK. Cancer mortality by age Cancer Research UK.2014. Available from: http://www.cancerresearchuk.o rg/health-professional/cancer-statistics/mortalit $\mathrm{y} \#$ heading-Two

[3] Statistics Norway. Dødsårsaker Statistics Norway. 2014. Available from: http://www.ssb.no/helse/statistikker/dodsårsak

[4] Payne S, Smith P, Dean S. Identifying the concerns of informal carers in palliative care. Palliative Medicine. 1999; 13: 37-44. PMid: 10320874. https://doi.org/10.1191/026921699673763725

[5] Grande GE, Stajduhar K, Aoun S, et al. Supporting lay carers in end of life care: Current gaps and future priorities. Palliative Medicine. 2009; 23: 339-44. PMid: 19304804. https://doi.org/10.1177/ 0269216309104875

[6] Murray MA, Fiset V, Young S. Where the Dying Live: A Systematic Review of Determinants of Place of End-of-Life Cancer Care. Oncology Nursing Forum. 2009; 36: 69-77. PMid: 19136340. https://doi.org/10.1188/09.0NF.69-77

[7] Neergaard MA, Jensen AB, Sondergaard J, et al. Preference for placeof-death among terminally ill cancer patients in Denmark. Scandinavian Journal of Caring Sciences. 2011; 25: 627-36. PMid: 21362004. https : //doi.org/10.1111/j.1471-6712.2011.00870.x

[8] Lowenstein A, Gilbar O. The Perception of Caregiver Burden on the Part of Elderly Cancer Patients, Spouses and Adult Children. Families, Systems \& Health. 2000; 18: 337-46. https ://doi .or g/10.1037/h0091862

[9] Grov EK, Fosså SD, Dahl AA. Is somatic comorbidity associated with more somatic symptoms, mental distress, or unhealthy lifestyle in elderly cancer survivors? Journal of Cancer Survivors. 2009; 3: 109-16.

[10] Northfield S, Nebauer M. The Caregiving Journey for Family Members of Relatives With Cancer: How Do They Cope? Clinical Journal of Oncology Nursing. 2010; 14: 567-77.

[11] Deeken JF, Taylor KL, Mangan P, et al. Care for the Caregivers: A Review of Self-Report Instruments Developed to Measure the Burden, Needs, and Quality of Life of Informal Caregivers. Journal of Pain and Symptom Management. 2003; 26: 922-53. https : //doi.org/10.1016/S0885-3924(03)00327-0

[12] Andershed B, Ternestedt BM. Relatives in end-of-life care - part 1: A systematic review of the literature the five last years, January 
1999-February 2004. Journal of Clinical Nursing. 2006; 15

[13] Grov EK, Dahl AA, Moum T, et al. Anxiety, depression, and quality of life in caregivers of patients with cancer in late palliative phase. Annals of Oncology. 2005; 16: 1185-91. PMid: 15849218. https://doi.org/10.1093/annonc/mdi210

[14] Given B, Wyatt G, Given C, et al. Burden and Depression Among Caregivers of Patients With Cancer at the End of Life. Oncology Nursing Forum. 2004; 31: 1105-17. PMid: 15547633. https: //doi.org/10.1188/04.0NF.1105-1117

[15] Hudson PL, Hayman-White K. Measuring the Psychosocial Characteristics of Family Caregivers of Palliative Care Patients: Psychometric Properties of Nine Self-Report Instruments. Journal of Pain and Symptom Management. 2006; 31: 14. PMid: 16563316. https://doi.org/10.1016/j.jpainsymman.2005.07.010

[16] Grov EK, Dahl AA. Quality of Life Measures in Caregivers of Patients with Cancer. In: Preedy R, V., Watson RR, editors. Handbook of Disease Burdens and Quality of Life Measures. New York, NY: Springer New York; 2010.

[17] Kinsella G, Cooper B, Picton C, et al. A Review of the Measurement of Caregiver and Family Burden in Palliative Care. Journal of Palliative Care. 1998; 14: 37-45. PMid: 9686494. https: //doi.org/10.1177/082585979801400206

[18] Kim Y, Schulz R, Beach S. Family Caregivers' Strains: Comparative Analysis of Cancer Caregiving With Dementia, Diabetes, and Frail Elderly Caregiving. Journal of Aging and Health. 2008; 20: 483-503. PMid: 18420838. https://doi.org/10.1177/089826 4308317533

[19] Francis LE, Worthington J, Kypriotakis G, et al. Relationship quality and burden among caregivers for late-stage cancer patients. Supportive Care in Cancer. 2010; 18: 1429-36. PMid: 19898879. https://doi.org/10.1007/s00520-009-0765-5

[20] Grov EK, Fosså SD, Tønnessen A, et al. The caregiver reaction assessment: Psychometrics, and temporal stability in primary caregivers of norwegian cancer patients in late palliative phase. Psycho-Oncology. 2006; 15: 517-27. PMid: 16189843. https://doi.org/10.1002/ pon. 987

[21] Utne I, Miaskowski C, Paul M, et al. Association between hope and burden reported by family caregivers of patients with advanced cancer. Supportive Care in Cancer. 2013; 21: 2527-35. PMid: 23625020. https://doi.org/10.1007/s00520-013-1824-5

[22] Milbury K, Badr H, Fossella F, et al. Longitudinal association between caregiver burden and patient and spouse distress in couples coping with lung cancer. Supportive Care in Cancer. 2013; 21: 23719. PMid: 23546537. https://doi.org/10.1007/s00520-013 $-1795-6$

[23] Park C, Sin WD, Choi YJ, et al. Determinants of the burden and positivity of family caregivers of terminally ill cancer patients in Korea. Psycho-Oncology. 2012; 21: 282-90. PMid: 22383270. https://doi.org/10.1002/pon.1893

[24] Lee KC, Chang CW, Chou CW, et al. Longitudinal Changes and Predictors of Caregiving Burden While Providing End-of-Life Care for Terminally Ill Cancer Patients. Journal of Palliative Medicine. 2013; 16: 632-7. PMid: 23556989. https://doi.org/10.1089/ jpm. 2012.0499

[25] Friedemann M, Buckwalter CK. Family Caregiver Role and Burden Related to Gender and Family Relationships. Journal of Family Nursing. 2014; 20: 313-36. PMid: 24777069. https://doi.org/10.1 $177 / 1074840714532715$

[26] Goldstein NE, Concato J, Fried TR, et al. Factors Associated With Caregiver Burden Among Caregivers of Terminally Ill Patients With Cancer. Journal of Palliative Care. 2004; 20: 38-43. PMid: 15132075 https://doi.org/10.1177/082585970402000108
[27] Kim Y, Baker F, Spillers RL. Cancer Caregivers' Quality of Life: Effects of Gender, Relationship, and Appraisal. Journal of Pain and Symptom Management. 2007; 34: 294-304. PMid: 17572056. https://doi.org/10.1016/j.jpainsymman.2006.11.012

[28] Lund L, Ross L, Petersen AM, et al. Cancer caregiving tasks and consequences and their associations with caregiver status and the caregiver's relationship to the patient: a survey. BMC Cancer. 2014; 14(541): 1-13. PMid: 25069703. https://doi .org/10.1186/14 71-2407-14-541

[29] Funk L, Stajduhar KI, Toye C, et al. Part 2: Home-based family caregiving at the end of life: A comprehensive review of published qualitative research (1998-2008). Palliative Medicine. 2010; 24(6): 594-607. PMid: 20576673. https://doi.org/10.1177/026921 6310371411

[30] Cutrona C, Russel D, Rose J. Social Support and Adaption to Stress by the Elderly. Journal of Psychology and Aging. 1986; 1(1): 47-58. PMid: 3267379. https://doi.org/10.1037/0882-7974.1.1. 47

[31] Gaugler EJ, Hanna N, Linder J, et al. Cancer caregiving and subjective stress: A multi-site, multi-dimensional analysis. Psychooncology. 2005; 14: 771-85. PMid: 15750995. https://doi.org/ $10.1002 /$ pon. 916

[32] Lyyra TM, Heikkinen RL. Perceived Social Support and Mortality in Older People. The Journals of Gerontology Series B: Psychological Sciences and Social Sciences. 2006; 61: 147-52. PMid: 16670192 https://doi.org/10.1093/geronb/61.3.S147

[33] Uchino BN. Understanding the Links Between Social Support and Physical Health. Perspectives on Psychological Science. 2009; 4 236-55. PMid: 26158961. https://doi.org/10.1111/j.1745 $-6924.2009 .01122 . \mathrm{x}$

[34] Wright LM, Leahey M. Nurses and Families: A Guide to Family Assessment and Interventions. 6th ed. Philadelphia, PA: F.A. Davis Company; 2013.

[35] Weiss R. The Provisions of Social Relationships. In: Rubin Z, editor Doing Unto Others. Englewood Cliffs, Prentice-Hall; 1974. 17-26 p.

[36] Shieh S, Tung S, Liang Y. Social Support as Influencing Primary Family caregiver Burden in Taiwanese Patients With Colorectal Cancer Journal of Nursing Scholarship. 2012; 44: 223-31. PMid: 22726108 https://doi.org/10.1111/j.1547-5069.2012.01453.x

[37] Daly BJ, Douglas S, Lipson A, et al. Needs of Older Caregivers of Patients with Advanced Cancer. Journal of the American Geriatrics Society. 2009; 57: 293-5. PMid: 20122032. https ://doi .org/10 $.1111 / j .1532-5415.2009 .02516 . x$

[38] Sharpe L, Butow P, Smith C, et al. The relationship between available support, unmet needs and caregiver burden in patients with advanced cancer and their carers. Psycho-oncology. 2005; 14: 102-14. PMid: 15386783. https://doi.org/10.1002/pon. 825

[39] Grunfeld E, Coyle D, Whelan T, et al. Family caregiver burden: results of a longitudinal study of breast cancer patients and their principal caregivers. Canadian Medical Assosiation Journal. 2004; 170: 1795-801. https://doi.org/10.1503/cmaj. 1031205

[40] Grov EK, Fosså SD, Sørebø Ø, et al. Primary caregivers of cancer patients in the palliative phase: A path analysis of variables influencing their burden. Social Science \& Medicine. 2006; 63: 242939. PMid: 16887247. https://doi.org/10.1016/j.socscime d. 2006.06 .008

[41] Sloan J, Vargas-Chanes D, Kamath CC, et al. Detecting worms, ducks, and elephants: A simple approach for defining clinically relevant effects in quality-of-life measures. Journal of Cancer Integrative Medicine. 2003; 1(1): 41-47.

[42] Given C, Given B, Stommel M, et al. The Caregiver Reaction Assessment (CRA) for Caregivers to Persons with Chronic Physical 
and Mental Impairments. Research in Nursing \& Health. 1992; 15: 271-83. https://doi.org/10.1002/nur.4770150406

[43] Russell D, Cutrona C, Rose J, et al. Social and Emotional Loneliness: An Examination of Weiss's Typology of Loneliness. Journal of Personality and Social Psychology. 1984; 46: 1313-21. PMid: 6737214. https://doi.org/10.1037/0022-3514.46.6.1313

[44] Kvaal K, Halding A, Kvigne K. Social provision and loneliness among older people suffering from chronic physical illness. A mixedmethods approach. Scand J Caring Sci. 2014; 28: 104-11. PMid: 23550895. https://doi.org/10.1111/scs.12041

[45] Bondevik M. The life of the oldest old. Bergen, Norway: University of Bergen; 1997.

[46] Hyden LC, Bulow PH. Who's talking: Drawing conclusions from focus groups. Some methodological considerations. International Journal of Social Research Methodology. 2003; 6: 305-21.

[47] Uphold CR, Harper DC. Methodological issues in intergenerational family nursing research. Advances in Nursing Science. 1986; 8: 3849. https ://doi.org/10.1097/00012272-198604000-00006

[48] Pinquart M, Sørensen S. Spouses, Adult Children and Childrenin-Law as Caregivers of Older Adults: A Meta-Analytic Comparison. Psychology and Aging. 2011; 26: 1-14. PMid: 21417538. https://doi.org/10.1037/a0021863

[49] Molassiotis A, Wilson B, Blair S, et al. Living with multiple myeloma: experiences of patients and their informal caregivers. Supportive Care in Cancer. 2011; 19: 101-11. PMid: 19998045. https ://doi.org/10.1007/s00520-009-0793-1
[50] Syren SM, Saveman B, Benzein EG. Being a Family in the Midst of Living and Dying. Journal of Palliative Care. 2006; 22: 26-32. PMid: 16689412. https : //doi.org/10.1177/082585970602200105

[51] Fjose M, Eilertsen G, Kirkevold M, et al. A Valuable but Demanding Time - Family Life During Advanced Cancer in an Elderly Family Member. Advances in Nursing Science. 2016; 39(4): 358-73. PMid: 27618695. https://doi.org/10.1097/ANS.00000000 00000145

[52] McLean S, Gomes B, Higginson I. The intensity of caregiving is a more important predictor of adverse bereavement outcomes for adult-child than spousal caregivers of patients who die of cancer. Psycho-Oncology. 2016; 1-7.

[53] Yoon JS, Kim SJ, Jung GJ, et al. Modifiable factors associated with caregiver burden among family caregivers of terminally ill Korean cancer patients. Supportive Care in Cancer. 2014; 22: 1243-50. PMid: 24424483. https://doi.org/10.1007/s00520-013-2077-z

[54] Clarke SA, Booth ML, Velikova G, et al. Social Support: Gender Differences in Cancer Patients in the United Kingdom. Cancer Nursing. 2006; 29(1): 66-72. https://doi .org/10.1097/00002820 $-200601000-00012$

[55] Jordhøy M, Kaasa S, Fayers P, et al. Challenges in palliative care research; recruitment, attrition and compliance: Experience from a randomized controlled trial. Palliative Medicine. 1999; 13: 299310. PMid: 10659099. https://doi .org/10.1191/0269216996 68963873 